\title{
Impact of Anticoagulants on Assessment of Zinc in Plasma
}

\author{
Jasna Jablan, Marija Grdić Rajković, Suzana Inić, Roberta Petlevski, Ana-Marija Domijan*
}

\author{
University of Zagreb, Faculty of Pharmacy and Biochemistry, A. Kovačića 1, HR-10000 Zagreb, Croatia \\ * Corresponding author's e-mail address: adomijan@pharma.hr
}

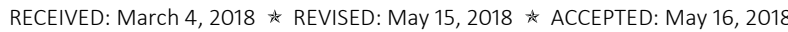

\begin{abstract}
The aim of this study was to compare zinc (Zn) level in EDTA, heparin, citrate plasma and serum. The blood samples from the same healthy volunteers $(n=10)$ were sampled by use of different anticoagulants (EDTA, heparin and citrate) or with no anticoagulant. Zn level was determined by flame atomic-absorption spectrometer (AAnalyst 800, PerkinElmer, USA). Zn level in EDTA, heparin, citrate plasma and serum was in reference range $\left(0.7\right.$ to $\left.1.5 \mu \mathrm{g} \mathrm{mL}^{-1}\right)$, and the difference between sample groups was not observed $(P=0.079)$. However, correlation was observed only between $\mathrm{Zn}$ level in heparin plasma and citrate plasma $\left(r_{\mathrm{s}}=0.72 ; P=0.016\right)$ and citrate plasma and serum $\left(r_{\mathrm{s}}=0.76 ; P=0.012\right)$. In conclusion, in Zn blood analysis, sample collection step is important and should be observed when planning study and when comparing the results of $\mathrm{Zn}$ level from various studies.
\end{abstract}

Keywords: anticoagulants, atomic-absorption spectrometer, serum, plasma, zinc.

\section{INTRODUCTION}

$\mathbf{T}$

RACE element zinc $(Z n)$ is essential to all organisms. In human body $\mathrm{Zn}$, as a component of more than 300 enzymes, participates in the synthesis and degradation of carbohydrates, lipids, proteins and nucleic acids, and thus is required for normal cell growth, division and integrity. ${ }^{[1,2]} \mathrm{Zn}$ requirements are the highest for infants (120-140 $\mu \mathrm{g} \mathrm{kg}^{-1}$ b.w. / day) and adolescents (60-80 $\mu \mathrm{g}$ $\mathrm{kg}^{-1}$ b.w. / day) while adult requirement is lower (30-40 $\mu \mathrm{g} \mathrm{kg}^{-1}$ b.w. / day). ${ }^{[1]}$ The clinical manifestations of $\mathrm{Zn}$ deficiency include: growth retardation, delayed sexual and bone maturation, skin lesions, diarrhoea, alopecia, impaired appetite, defect of immune system and behavioural changes. ${ }^{[1]}$ Development of some chronic diseases such as atherosclerosis, neurological disorders, autoimmune diseases, ageing and cancers are associated with $\mathrm{Zn}$ deficiency. ${ }^{[2]}$ However, high concentration of $\mathrm{Zn}$ is toxic (signs of $Z n$ toxicity: nausea, vomiting, diarrhoea and fever), so upper intake level of $\mathrm{Zn}$ for adults is set at $45 \mathrm{mg} /$ day. ${ }^{[1]}$ Therefore, monitoring $\mathrm{Zn}$ levels in human biological samples is important.

In order to associate the level of $\mathrm{Zn}$ with the development of specific human disease, numerous studies have monitored its level in biological fluids such as plasma, serum or urine. ${ }^{[3-5]}$ However, in some studies, sample collection and sample preparation step is not clearly described. ${ }^{[6]}$

Due to their physiological functions, the levels of trace elements inside and outside the cell are different. Therefore, collection of plasma/serum sample is the most critical step for trace element analysis. ${ }^{[7]}$ For example iron (Fe) and $\mathrm{Zn}$ levels in erythrocyte are 10-times higher than in plasma and haemolysis or micro-haemolysis can give false higher results of $\mathrm{Fe}$ and $\mathrm{Zn}$ in plasma. Also, anticoagulants can affect the level of trace elements in plasma since anticoagulants cause fluid shift (inside / outside cell). Additionally, the use of anticoagulants that chelate metals ions (such as EDTA and citrate) is limited. Thus for trace element analysis it is important to standardise the method of pre-analysis, i.e. sample collection step as well. However, due to multi-parameter analysis and study limitations, such as sample size, in some studies sample collection is neglected. Therefore, the aim of this study was to test various anticoagulants normally used in clinical laboratories (EDTA, heparin and citrate) and compare the level of $\mathrm{Zn}$ detected in obtained plasma and serum. 


\section{EXPERIMENTAL}

\section{Samples}

Blood samples were collected from 10 healthy volunteers (Caucasians, aged 30-48 years, of both genders), from Zagreb (Croatia), all of which had an annual medical check-up at Clinical Hospital Centre "Sestre Milosrdnice", Zagreb, Croatia. The blood samples were collected in the morning (between 8.00 and 9.00 a.m.) from fasting subjects. The exclusion criteria were the use of vitamin and/or mineral supplements in the past month. From each volunteer venous blood was collected in sterile conditions in plastic (PET) blood collection tubes containing $\mathrm{K}_{3} \mathrm{EDTA}$, lithium heparin and trisodium citrate solution as anticoagulant (Greiner Bio-One, Kremsmünster, Austria) or in serum tubes (Greiner Bio-One, Kremsmünster, Austria) to obtain serum. To obtain plasma, tubes were immediately centrifuged (4000 rpm / $10 \mathrm{~min}$ ), and to obtain serum, tubes were left to sit for $30 \mathrm{~min}$, and then centrifuged (4000 rpm / $10 \mathrm{~min}$ ). Plasma or serum was transferred to polyethylene Eppendorf tubes and stored at $-20^{\circ} \mathrm{C}$ until analysis. During sample collection procedure it was taken care that no $\mathrm{Zn}$ contamination occurs.

All the participants signed the informed consent form and approved their participation in the study. The study was approved by the Clinical Hospital Centre "Sestre Milosrdnice" Ethics Committee and conducted in accordance with the ethical principles of the Declaration of Helsinki.

\section{Standard Preparation}

Standard stock solution of $\mathrm{Zn}\left(1000 \mu \mathrm{gL}^{-1}\right.$ in $\left.2 \% \mathrm{HNO}_{3}\right)$ was procured from PerkinElmer (Waltham, MA, USA). Working standards in concentration range $\left(0.05-1.0 \mu \mathrm{g} \mathrm{mL}^{-1}\right)$ were prepared fresh daily by dissolving stock solution in MilliQ water.

All glassware used for standard preparation was soaked in $15 \% \mathrm{HNO}_{3}$ (p.a. Kemika, Zagreb, Croatia) overnight, and thoroughly rinsed with MilliQ water before use.

\section{Equipment}

Analysis of $\mathrm{Zn}$ level was performed on flame atomicabsorption spectrometer, FAAS (AAnalyst 800 PerkinElmer,

Table 1. Optimal conditions set of flame atomic-absorption spectrometer (FAAS) for Zn analysis in plasma and serum.

\begin{tabular}{cc}
\hline Type of flame / fuel & Acetylene / air \\
Wavelength & $213.9 \mathrm{~nm}$ \\
Slit width & $0.7 \mathrm{~nm}$ \\
Lamp current & $15 \mathrm{~mA}$ \\
\hline
\end{tabular}

Waltham, MA, USA) with deuterium background corrector (DBC). The results were collected and processed by AAWinlab 32 Software (PerkinElmer, Waltham, MA, USA).

For $\mathrm{Zn}$ analysis FAAS was set as follows: hallow cathode lamp at $15 \mathrm{~mA}$ and $\lambda=213.9 \mathrm{~nm}$; as oxidants acetylene / air was used (pressure / flow: $0.9 \times 10^{5}$ / 5; 5.5×10 / 17 for acetylene and air, respectively) (Table 1 ).

\section{Sample Procedure}

Sample procedure step was performed according to the standard method described by PerkinElmer ${ }^{[8]}$ with minor modification. Plasma or serum samples were thawed and centrifuged ( $9000 \mathrm{rpm} / 3 \mathrm{~min}$ ) to remove debris that could clog FAAS. Afterwards, samples were diluted with MilliQ water $(5 x)$, homogenised and aspirated to FAAS. Concentration of $\mathrm{Zn}$ was calculated from calibration curve. Each sample was analysed in triplicate and results have been reported as a mean value. Plastic (polyethylene) tubes were used throughout sample preparation procedure.

\section{Statistical Analysis}

Data are presented as a median and interquartile range and, to be able to compare the results with other studies, as a mean \pm standard deviation. The difference in $\mathrm{Zn}$ concentration in EDTA, heparin, citrate plasma and serum was tested with Kruskal-Wallis One-Way Analysis of Variance Ranks. To test for correlation, Spearman correlation was used. Probability values of $P<0.05$ were considered statistically significant. For statistical analysis, Sigma Stat 3.0 was used.

\section{RESULTS AND DISCUSSION}

\section{Selection of Analytical Technique}

Nowadays, AAS (flame or graphite), inductively coupled plasma atomic emission spectroscopy (ICP-AES), inductively coupled plasma mass spectrometry (ICP-MS) or X-ray fluorescence spectrometry is used for the assessment of trace elements in biological samples. Analytical techniques, such as ICP-AES, ICP-MS or total reflection X-ray fluorescence (TXRF), allow multi-element analysis and have lower limit of detection (as low as ppq, 1015), thus in comparison with AAS they need smaller sample volume, and have better sensitivity. Nevertheless, AAS is still used for trace elements analysis in the majority of clinical laboratories. AAS is robust, sample preparation is not time consuming, and handling of instrument is simple, making the analysis costeffective.

\section{Validation of the Method}

The method validation parameters are presented in Table 2. The linearity of the method was tested by preparing 


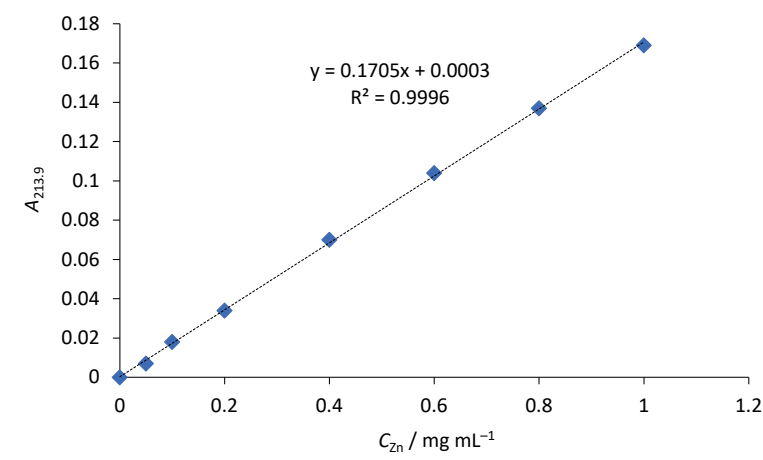

Figure 1. The calibration curve obtained from $\mathrm{Zn}$ standards in concentration range $0.05-1.0 \mu \mathrm{g} \mathrm{mL}$.

calibration curve from working Zn standards in MilliQ water in concentration range from 0.05 to $1.0 \mu \mathrm{g} \mathrm{mL}^{-1}$. Due to the dilution of plasma / serum samples $0.05 \mu \mathrm{g} \mathrm{mL} \mathrm{L}^{-1}$ standard was included in the calibration curve. The calibration curve was linear (correlation coefficient, $R^{2}=0.9996$; Figure 1). The sensitivity of the method was given as limit of detection (LOD) and limit of quantification (LOQ). LOD was calculated as 3.3 times standard deviation of the intercept divided with slope of calibration curve and it was $0.01 \mu \mathrm{g} \mathrm{mL}^{-1}$. LOQ was calculated as 10 times standard deviation of the intercept divided by the slope of calibration curve and it was $0.04 \mu \mathrm{g} \mathrm{mL}-1$.

For precision (repeatability and reproducibility) experiments pooled serum sample was obtained. The pooled serum sample was prepared as described in Sample Procedure and aspired to the FAAS in ten replicates within the day. The calculated mean coefficient of variation (CV) for repeatability (intraday precision) was below $1.0 \%$. For reproducibility (inter day precision) the sample of pooled serum was aspired to the FAAS trough six consecutive days and calculated mean $\mathrm{CV}$ was $1.0 \%$. These data indicate high precision of the method.

For accuracy experiment a certificate reference material (CRF) Human Multi-Sera Level 3 (Randox, Crumlin, UK) was used. CRF was prepared as described in Sample Procedure, aspired to FAAS and analysed in triplicate. The calculated accuracy of the method was $101.06 \%$.

Table 2. Validation parameters of the method for determination of $\mathrm{Zn}$ level in plasma and serum by flame atomic-absorption spectrometer (FAAS).

\begin{tabular}{cc}
\hline Limit of detection, LOD / $\mu \mathrm{g} \mathrm{mL}^{-1}$ & 0.01 \\
Limit of quantification, LOQ / $\mu \mathrm{g} \mathrm{m}^{-1}$ & 0.04 \\
Repeatability / \% & 0.72 \\
Reproducibility / \% & 1.0 \\
Accuracy / \% & 101.06 \\
\hline
\end{tabular}

\section{Influence of Anticoagulants on $\mathrm{Zn}$ Level Detected in Plasma}

Several factors affect blood $\mathrm{Zn}$ level. Nutrition is one factor. After the meal immediate increase of serum $\mathrm{Zn}$ level is observed. ${ }^{[9]}$ Also, diurnal variations in serum $\mathrm{Zn}$ level among fasted individuals is recorded. ${ }^{[9]}$ Both these factors should be observed when collecting blood for $\mathrm{Zn}$ analysis. However, in trace element analysis the most critical step is sample collection. ${ }^{[7]}$ This is especially important for $\mathrm{Zn}$, since $\mathrm{Zn}$ level is higher in the cell than in extracellular fluid. Milne ${ }^{[7]}$ stated that $\mathrm{Zn}$ level is $5-15 \%$ higher in serum than in plasma because of the release of $\mathrm{Zn}$ from erythrocytes and platelets during clotting. Additionally, anticoagulants can cause osmotic fluid shifts from blood cells, thus leading to plasma dilution. Therefore, for $\mathrm{Zn}$ analysis, as biological sample, serum is preferred over plasma.

In this study several anticoagulants, commonly used in clinical laboratory, were selected and $\mathrm{Zn}$ level in obtained plasma was compared to $\mathrm{Zn}$ level in serum. Previous studies compared $\mathrm{Zn}$ level detected in plasma to $\mathrm{Zn}$ level detected in serum. However, in those studies either only one type of plasma sample (heparin plasma) ${ }^{[10]}$ was used, or the type of plasma sample (type of anticoagulant used) was not stated. ${ }^{[11]}$ More detailed study was done by Frank et. al.[12] however, citrate plasma was not included in that study. Therefore, in this study, the $\mathrm{Zn}$ level detected in EDTA, heparin and citrate plasma samples, was compared to the $\mathrm{Zn}$ level detected in serum samples. The obtained results are presented in Table 3. In this study, the $\mathrm{Zn}$ level detected in EDTA, heparin, citrate plasma or serum was within the accepted reference interval 0.7 to $1.5 \mu \mathrm{g} \mathrm{mL}^{-1}$ (10.7 to $\left.22.9 \mu \mathrm{mol} \mathrm{L}^{-1}\right)^{[7]}$ and was similar to the one reported in previous studies for healthy (control) subjects. In the study by Wei-Jie et. al. ${ }^{\left[{ }^{[9]}\right.}$ the $\mathrm{Zn}$ level in serum and heparin plasma of healthy individuals determined by FAAS was $0.87 \pm$ $0.22 \mu \mathrm{g} \mathrm{mL}-1$ and $0.90 \pm 0.24 \mu \mathrm{g} \mathrm{mL}-1$, respectively. Similarly, Prasad et. al. ${ }^{[4]}$ reported serum $\mathrm{Zn}$ level of 12.71 $\pm 3.24 \mu \mathrm{mol} \mathrm{L}^{-1}$ (equivalent to $0.83 \pm 0.21 \mu \mathrm{g} \mathrm{mL}^{-1}$; assessed by FAAS) in control subjects and Feng et. al. ${ }^{[3]}$ reported serum $\mathrm{Zn}$ level of $1.06 \mu \mathrm{g} \mathrm{mL}^{-1}$ (assessed by FAAS) in control subjects.

Statistical analysis revealed that $Z n$ level in EDTA, heparin and citrate plasma and $\mathrm{Zn}$ level in serum did not differ (Table 3; $P=0.079$ ). This is in agreement with previous observation of Wei-Jie et. al. ${ }^{[9]}$ who demonstrated that there is no difference in $\mathrm{Zn}$ level detected in heparin plasma and $\mathrm{Zn}$ level detected in serum. Also, Makino and Takahara ${ }^{[10]}$ observed no difference in $\mathrm{Zn}$ level between serum and plasma (in this study the type of plasma / anticoagulant used was not specified). On the other hand, in the study of Frank et. al., ${ }^{[12]}$ in which the $\mathrm{Zn}$ level in serum and several types of plasma samples were compared, significantly higher Zn level was detected in EDTA plasma. 
Table 3. Zn level in EDTA, heparin, citrate plasma and serum.

\begin{tabular}{|c|c|c|c|c|c|}
\hline & EDTA & heparin & citrate & serum & $P^{(\mathrm{a})}$ \\
\hline Median (interquartile range) / $\mu \mathrm{g} \mathrm{mL}^{-1}$ & $0.905(0.811-0.949)$ & $0.863(0.780-1.040)$ & $0.740(0.690-0.805)$ & $0.900(0.794-0.911)$ & 0.079 \\
\hline Mean $\pm \mathrm{SD}^{(b)} / \mu \mathrm{g} \mathrm{mL}^{-1}$ & $0.88 \pm 0.11$ & $0.89 \pm 0.16$ & $0.76 \pm 0.09$ & $0.88 \pm 0.14$ & \\
\hline
\end{tabular}

The higher level of $\mathrm{Zn}$ in EDTA plasma was related to the contamination of collection container / anticoagulant with $\mathrm{Zn}$. The authors analysed EDTA in the collection containers and found that the $\mathrm{Zn}$ level in EDTA containers was $0.7 \pm 0.4$ $\mu \mathrm{g} \mathrm{mL} \mathrm{m}^{-1}$. Such high $\mathrm{Zn}$ concentration contributed to the higher level of Zn detected in EDTA plasma. In this study, all the used types of collection tubes were tested for the presence of $\mathrm{Zn}$, and in collection tubes (with EDTA, heparin and citrate as anticoagulants and for serum) detected $\mathrm{Zn}$ level was below LOQ. In the study by Frank et. al. ${ }^{[12]}$ glass collection tubes (producer was not specified) were used, whereas in this study collection tubes were made of PET plastic (as specified by the producer). It can thus be concluded that the blood collection tube production technique improved over time (2001-2018), and that no contamination occurs as a consequence. Although in this study no statistical difference in $\mathrm{Zn}$ level between EDTA, heparin, citrate plasma and serum was observed, the lowest $\mathrm{Zn}$ level was detected in citrate plasma. Compared to the other types of samples, $\mathrm{Zn}$ level detected in citrate plasma was up to $18 \%$ lower. This could be due to reversible binding of calcium ions by citrate, ${ }^{[13]}$ thus citrate except calcium ions is able to bind $\mathrm{Zn}$ leading to lower $\mathrm{Zn}$ level in citrate plasma.

Furthermore, results of Zn level in EDTA, heparin, citrate plasma or serum were tested for correlation. Correlation coefficients $\left(r_{s}\right)$ are presented in Table 4 . Correlation was observed only between $\mathrm{Zn}$ level in heparin plasma and citrate plasma $\left(r_{\mathrm{s}}=0.72 ; P=0.016\right)$ and citrate plasma and serum $\left(r_{s}=0.76 ; P=0.012\right)$. Lack of correlation between the sample groups points to the importance of sample collection step in $\mathrm{Zn}$ blood analysis. When planning the study, it is important to set protocol for blood collection and that only one type of collection tube is used. Use of

Table 4. Spearman's correlations coefficients $\left(r_{s}\right)$ and level of significance $(P)$ between $\mathrm{Zn}$ levels in EDTA, heparin, citrate plasma and serum samples.

\begin{tabular}{cccc}
\hline & Serum & Citrate & Heparin \\
& $r_{\mathrm{s}} ; P$ & $r_{\mathrm{s}} ; P$ & $r_{\mathrm{s}} ; P$ \\
\hline EDTA & $0.60 ; 0.102$ & $0.58 ; 0.087$ & $0.65 ; 0.050$ \\
Serum & - & $0.76 ; 0.012$ & $0.54 ; 0.124$ \\
Citrate & & - & $0.72 ; 0.016$ \\
\hline
\end{tabular}

collection tubes for trace element is recommended, but in the case of multi-parameter analysis, or lack of the sample, only one type of sample should be used. Also, the type of sample (serum/plasma) and anticoagulant should be considered when comparing results from different studies.

\section{CONCLUSION}

Since trace element $\mathrm{Zn}$ has numerous functions in the body and is associated with the development of human chronic diseases, numerous studies monitor its level in biological samples. This study confirms that FAAS is a simple, precise and robust analytical technique that gives reliable results for $\mathrm{Zn}$ level in plasma or in serum. Although this study found that there is no difference in the $\mathrm{Zn}$ level detected in plasma samples obtained by use of various anticoagulants and in serum, the lowest $\mathrm{Zn}$ level was detected in citrate plasma. Additionally, correlation was observed only between $\mathrm{Zn}$ level in citrate and heparin plasma samples and citrate plasma samples and serum samples. Therefore, collection of plasma/serum samples is an important step in Zn blood analysis and should not be neglected when planning the study and comparing results from different studies.

Acknowledgment. The authors greatly acknowledge the financial support of the University of Zagreb.

\section{REFERENCES}

[1] WHO, Vitamin and mineral requirements in human nutrition, Second edition, World Health Organisation and Food and Agriculture Organisation of the United Nations, Geneva, 2004.

[2] C. T. Chasapis, A. C. Loutsidou, C. A. Spiliopoulou, M. E. Stefanidou, Arch. Toxicol. 2012, 86, 521.

[3] J. F. Feng, L. Lu, P. Zeng, Y-H. Yang, J. Luo, Y-W. Yang, D. Wang, Int. J. Clin. Oncol. 2012, 17, 575.

[4] D. K. V. Prasad, U. Shaheen, U. Satyanaryana, T. Surya Prabha, A. Jyothy, A. Munshi, Neurochem. Res. 2014, 39, 2370.

[5] L. Bermudez, C. Garcia-Vicent, J. Lopez, M. I. Torro, E. Lurbe, J. Translat. Med. 2015, 13, 291.

[6] C.-H. Guo, P-C. Chen, M.-S. Yeh, D.-Y. Hsiung, C,-L. Wang, Clin. Biochem. 2011, 44, 275. 
[7] D. B. Milne, in Clinical nutrition of the essential trace elements and minerals: the guide for healthy professionals (Eds. J. D: Bogden, and L. M. Klevey), Humana Press, Totowa, NJ, 2000, pp 69-90.

[8] Analytical Methods for Atomic Absorption Spectrometry, Atomic Spectrometry, PerkinElmer, 2000, pp.160-161.

[9] N. Roohani, R Hurrell, R Kelishadi, R Schulin, J. Res.
Med. Sci. 2013, 18, 144.

[10] C. Wei-Jie, Z. Cheng-Yi, Z. Tian-Li, Clin. Chim. Acta 1986, 155, 185.

[11] T. Makino, K. Takahara, Clin. Chem. 1981, 27, 1445.

[12] E. L. Frank, M. P. Hughes, D. D. Bankson, W. L. Roberts, Clin. Chem. 2001, 47, 1109.

[13] G. Lee, G. M. Arepally, J. Clin. Apher. 2012, 27, 117. 